\title{
动 态
}

\section{新型高性能金属玻璃纤维应变传感器}

目前, 商业应变片的应变敏感材料是丝状或是箔状的, 因为它们的电阻率较低且不能做得很细, 所以其性能和可靠性都不太好. 尺寸更小的以单根应变敏感材料为敏感元件的应变传感器一直是人 们追求的目标, 自第一个商业化应变片诞生开始人们就一直致力于实现该目标. 而用传统的应变敏 感材料是无法实现的. 之前我们已经研究了金属玻璃纤维的压阻效应, 已经证实它们是一种性能优 异的应变敏感材料. 用高电阻率和极细的单根金属玻璃纤维做成的应变传感器能实现人们长期以来 追求的目标.

由中国科学院物理研究所博士生导师汪卫华研究员担任通讯作者, 博士生易军撰写的《近理想 电阻式应变传感器—无祄底单股金属玻璃纤维》一文阐述了用高电阻率和极细的单股金属玻璃纤 维做成的应变传感器, 它是一种近理想的应变传感器。该文发表在 SCIENCE CHINA Physics, Mechanics \& Astronomy 第 55 卷第 4 期上 ${ }^{[1]}$.

第一个商业化的应变片是将康铜丝(直径为 $25 \mu \mathrm{m}$, 长度是 $200 \mathrm{~mm}$, 电阻值是 $120 \Omega$ ) 用环氧树 脂胶粘在两片香烟纸之间。这种应变片只能用于大型机械零件的静态应变分析. 这种应变片由于长 度太长而不能用于高梯度应变和小器件的应变分析. 而后, Gall 于 1944 年发明了一种将金属丝缠绕 成均匀拉伸的棚格状并粘在绝缘衬底材料上的方法, 但这种方法的工艺过程比较复杂. 1953 年, Jackson 发明了箔式应变片。而今箔式应变片几乎占领了全部的市场。桶格金属丝应变片和箔式应 变片的发明使得应变片的长度大大减小. 但是, 这两种应变片的应变敏感材料的构型带来了一系列 问题, 如箭滞、散热、由安装带来的性能降低, 不能被安装在曲面上, 根格末端造成的电阻变化, 横 向应变造成的电阻变化. 以单根应变敏感材料为敏感元件的应变传感器一直没能实现, 而且自箔式 应变片发明之后电阻式应变片的发展几乎处于停滞状态。

金属玻璃纤维应变传感器在尺寸大小和量程方面与箔式应变片相比所取得的先进进展表明金 属玻璃纤维应变传感器是一种近完美的电阻式应变传感器. 金属玻璃纤维应变传感器的量程是商业 化箢式应变片的 4-8.5 倍, 而其尺寸只有最小商业化箔式应变片的 1/16. 而且金属玻璃纤维应变传 感器电阻相对变化率 $\Delta R / R_{0}$ 与应变 $\varepsilon$ 关系曲线的线性度很高, 应变敏感系数很高, 强热稳定性, 高刚 度, 方便安装, 解决了箔式应变片带来的一系列问题. 性能优异的金属玻璃纤维应变传感器将在应 力分析和传感器的应变敏感元件上有广阔的应用前景. 该研究获得了国家自然科学基金(批准号: 50921091 和 50731008)和国家重点基础研究发展计划 973 项目(编号: 2007CB613904 和 2010CB731603).

1 Yi J, Huo L S, Zhao D Q, et al. Toward an ideal electrical resistance strain gauge using a bare and single straight strand metallic glassy fiber. Sci China-Phys Mech Astron, 2012, 55(4): 609-613 